BEST PRACTICE

\title{
Prostate cancer management: (1) an update on localised disease
}

\author{
S R J Bott, A J Birtle, C J Taylor, R S Kirby
}

Postgrad Med J 2003;79:575-580

Prostate cancer is receiving ever more publicity with the result that more men are having their prostate specific antigen checked and a greater proportion of men are diagnosed with potentially curable localised disease. Advances in the therapeutic modalities including radical surgery, external beam radiotherapy, and brachytherapy have reduced the incidence of side effects and now offer patients a choice of treatments depending on their tumour characteristics, age, and co-morbidity. A significant proportion of men do not need intervention and may be safely kept under a "watch and wait" policy. The use of genetic markers may in the future distinguish between patients most likely to benefit from radical therapy and those in who either palliation or observation is more appropriate. This review examines the potentially curative options, as well as expectant management, outlining the pros and cons of each. The use of adjuvant and neoadjuvant therapy is also discussed.
See end of article for authors' affiliations

Correspondence to: Mr Simon R J Bott, Prostate Cancer Research Centre, Charles Bell House, 67 Riding House Street, London WIW 7EY, UK; simonrjbott@hotmail.com

Submitted 17 January 2003 Accepted 24 May 2003

\section{INTRODUCTION AND INCIDENCE}

Prostate cancer is an enigma and while this makes it a fascinating disease to study it often makes it a difficult disease to treat. A male born in the Western world has a $40 \%$ lifetime risk of developing prostate cancer, yet only a $10 \%$ risk of becoming symptomatic and a 3\% risk of dying from this disease. ${ }^{1}$ So a significant proportion of men develop prostate cancer and lead a normal full and active life oblivious to what their prostate is harbouring. In the UK 21400 new cases of prostate cancer are diagnosed per annum, a rate of 74 cases per 100000 (National Statistics: http://www.statistics.gov. uk/ststbase/datasets2.asp). The age matched incidence, which gives a better indication of the true incidence of an age related disease within an ageing population, has actually been fairly constant over the last $7-8$ years. The age matched incidence in the United States is over twofold higher than in the UK, despite similar mortality rates-this probably reflects the greater use of prostate specific antigen (PSA) as a screening tool in America. Stamey et al published their seminal paper on the potential use of PSA in the diagnosis and management of prostate cancer in 1987. ${ }^{2}$ The incidence of prostate cancer in the US subsequently increased sharply in 1990 and then declined in 1993, until settling in 1995 to a level substantially higher than the 1986 level. ${ }^{3}$ The UK witnessed a slower increase in the age matched incidence up until 1994, since when the incidence has levelled off.

Prostate cancer is now the second leading cause of male cancer death in Europe and the US and is likely to overtake lung cancer in the near future. Despite this, the mortality rates have shown a downward trend in both countries since 1993, although the decrease is more dramatic in the US. Proponents of PSA screening have claimed these improved mortality rates reflect the rise in serum screening. ${ }^{4}$ Indeed the US and to a lesser extent the UK and Europe have witnessed a stage migration at diagnosis, where now a greater proportion of men are presenting with organ confined disease. ${ }^{6}$ However, for an effect on mortality in a disease with a protracted course there would be an expected lead time of 10-20 years-that is, we would expect to see a reduction in mortality over the next few years, rather than a decade ago. Furthermore the reduction in mortality witnessed across the US has been the same in regions of high and low levels of PSA screening. ${ }^{7}$ While PSA testing may have some role, improvements in treatment or some other factor must also be considered. ${ }^{3}$

\section{LOCALISED PROSTATE CANCER}

Localised prostate cancer is cancer that is confined to the prostate, or T2 or less (tumour, nodes, and metastasis (TNM) classification, Union Internationale Contre Cancer (UICC) 6th edition, 2002) (table 1) and 58\% of men diagnosed with prostate cancer in the UK present with this potentially curable localised disease. ${ }^{8}$

The prostate gland's anatomy complicates curative treatment. From a surgical perspective there is little surrounding fascia to take with the specimen to enhance the chance of resection margins clear of tumour. Furthermore, vital structures are in close proximity; the external sphincter lies just distal to the prostatic apex, the thin Denonvillier's fascia posteriorly separates the prostate and the rectum, and the trigone of the bladder abuts the prostatic base. The close proximity of these structures not only restricts cancer clearance surgically but also gives rise to the side effects experienced by some men after radiotherapy, as these may be included in the irradiated field.

Abbreviations: $\mathrm{Cl}$, confidence interval; EBRT, external beam radiotherapy; PSA, prostate specific antigen; TNM, tumour, nodes, and metastasis; UICC, Union

Internationale Contre Cancer 
Table 1 TNM classification of prostate cancer (UICC 6th edition, 2002)

\begin{tabular}{|c|c|}
\hline $\mathrm{T} 1$ & Impalpable and not visible on imaging \\
\hline Tla & Tumour incidental finding in $\leqslant 5 \%$ tissue resected at TURP \\
\hline $\mathrm{T} 1 \mathrm{~b}$ & Tumour incidental finding in $>5 \%$ tissue resected at TURP \\
\hline Tlc & Tumour identified by needle biopsy \\
\hline T2 & Tumour confined within the prostate \\
\hline $\mathrm{T} 2 \mathrm{a}$ & Tumour involves one half of one lobe, or less \\
\hline $\mathrm{T} 2 \mathrm{~b}$ & $\begin{array}{l}\text { Tumour involves more than one half of one lobe, but not } \\
\text { both lobes }\end{array}$ \\
\hline T2c & Tumour involves both lobes \\
\hline T3 & Tumour extends through the prostatic capsule \\
\hline T3a & Unilateral or bilateral extracapsular extension \\
\hline $\mathrm{T} 3 \mathrm{~b}$ & Tumour invades seminal vesicle(s) \\
\hline T4 & $\begin{array}{l}\text { Tumour is fixed or invades adjacent structures other than } \\
\text { the seminal vesicles: bladder neck, external sphincter, } \\
\text { rectum, levator muscles, or pelvic wall }\end{array}$ \\
\hline$N-X, 0,1$ & $\begin{array}{l}\text { Lymph nodes: not assessed, no regional metastases, } \\
\text { regional node metastases }\end{array}$ \\
\hline$M 1-a, b, c$ & $\begin{array}{l}\text { Distant metastases: non-regional lymph node metastases, } \\
\text { bone metastases, other site }\end{array}$ \\
\hline
\end{tabular}

To compound matters there is no preoperative examination or test that accurately predicts whether clinically localised prostate cancer is confined to the prostate pathologically. The three best investigations, namely the preoperative PSA, the Gleason grade of cancer at biopsy, and the digital rectal examination are often combined and fed into predictive nomograms, for example Partin's tables. These give an individual the likelihood that his cancer is organ confined based on a large series of American men. While these tables have been independently validated both in the US and in Europe $^{9}$ they still give an estimation based on a population rather than the individual concerned.

Men diagnosed with clinically localised prostate cancer essentially have three treatment options: radical surgery, radiotherapy (external beam radiotherapy (EBRT) or brachytherapy), and active surveillance (watch and wait). There have been no randomised controlled trials comparing surgery versus radiotherapy or brachytherapy. The results of the UK PROTEC study in which men with PSA screen detected tumours are randomised to receive surgery, EBRT, or active surveillance are awaited. In the meantime the decision is based on the nature of the cancer at biopsy-Gleason grade, number and site of cores involved, the PSA, the patient's comorbid status, and after a full discussion with the individual.

\section{Radical prostatectomy}

Radical prostatectomy involves the removal of the entire prostate, seminal vesicles and frequently the obturator lymph nodes, the latter for staging purposes. It is usually performed through an abdominal incision-the retropubic approach, alternatively the transperineal or laparoscopic techniques are employed. The incidence of tumour at the resection limit, a positive surgical margin, is similar for each technique but the location of the limits is dependent upon the approach. ${ }^{10}{ }^{12}$ The apex is the most common site for positive margins in the retropubic and laparoscopic approaches, while the anterior prostate is the most common site when using the perineal approach. ${ }^{10}{ }^{11}{ }^{13-15}$ Proponents of the transperineal route argue the intraoperative blood loss is less and, as there is no abdominal wound, postoperative pain is reduced. ${ }^{16}{ }^{17}$ However, the obturator lymph nodes cannot be sampled via this route, so either the nodes are not taken for staging or are taken laparosopically in a separate procedure. Moreover, it may be impossible to remove large prostates whole via this route. They are first bivalved and then removed in two pieces with at least a theoretical risk of tumour seeding.
The laparoscopic prostatectomy is a technically demanding procedure and there is a significant learning curve. ${ }^{18}$ Nevertheless this technique, sometimes aided by a robot, is becoming increasingly popular as the postoperative hospital stay is 2-4 days compared with 4-6 days after the conventional approach. Furthermore, as the anastomosis between the bladder and urethral stump is performed under magnification urinary continence may resume earlier. ${ }^{11} 19$

Whichever route is taken the disease specific outcomes are similar. Cancer cure rates at 10 years after radical surgery are in excess of $80 \%$ of men in the American series. ${ }^{20-22}$ Most men in North America are diagnosed by PSA screening and probably present earlier in the disease course. In the UK, a study with a limited median follow up of 25 months (range 2-89) after radical retropubic prostatectomy had a PSA-free survival of $78 \% .^{23}$ Longer term UK outcome data are awaited.

The first randomised study comparing cancer outcomes in men undergoing radical prostatectomy with a watch and wait policy was recently reported by Holmberg et al. ${ }^{24}$ They assigned 695 men with localised prostate cancer to either radical prostatectomy or active surveillance and after a median follow up of 6.2 years they reported their intermediate findings. At five years there was an absolute difference in disease-free survival in favour of radical prostatectomy of only $2 \%$ ( $95 \%$ confidence interval (CI) -0.8 to 4.8 ). However, after five years the disease specific mortality curves diverged such that there was an absolute difference in favour of surgery of $6.6 \%$ (95\% CI 2.1 to 11 ) at eight years from randomisation. In terms of a relative risk this represents a halving of the death rate due to prostate cancer at eight years. Unfortunately, this study raised as many questions as it answered. On the one hand benefit in terms of cancer specific survival was seen in only $6 \%$ of men undergoing radical prostatectomy compared with watch and wait at eight years and no benefit in terms of overall mortality from any cause was seen in either group (log rank test $\mathrm{p}=0.31$ ). On the other hand as this study recruited from 1989 the patient mix contained men who were older than most current series (64.7 years compared with 58 years in recent series $\left.{ }^{6}\right)$, and their patients had higher PSA levels and clinical stage disease before randomisation. What is more, nearly $10 \%$ of patients randomised actually opted for the opposite treatment. The results were given on an intention to treat basis and so if surgery is of benefit this would bias the results in favour of a watch and wait policy. Radical prostatectomy is undertaken in men with a life expectancy of at least 10 years, as the benefits of surgery are greatest beyond this period. The longer term results of this trial need to be procured before definitive conclusions can be drawn.

This study highlights the problems in performing adequate trials comparing the various treatment options in localised prostate cancer. As the disease has a protracted course by the time valid data have been accrued the population investigated is no longer representative of current practice. Furthermore, as a large amount of unrandomised data has been available on the outcomes of treatment for a number of years, randomly allocating patients a treatment against the background of these studies is difficult.

One of the advantages of surgically excising the prostate is that the serum PSA should fall to an undetectable level within a month of surgery. Regular follow up including PSA checks can detect recurrent disease eight years before metastases develop and if metastases develop a further five years before death from prostate cancer. ${ }^{25}$ In the event of a PSA rise further treatments can be offered including EBRT to the prostate bed if local recurrence is suspected or hormonal manipulation if systemic disease is evident. 


\section{Side effects of radical prostatectomy}

In 1982 Walsh and Donker published their seminal work on the anatomy of the dorsal venous complex and the cavernosal nerves. ${ }^{26}$ An understanding of the site of these blood vessels enables better intraoperative bleeding control; this improves vision and allows more accurate dissection around the urethral sphincter. Continence rates, as defined as "padfree", are as high as $95 \%$ in most large centres now,,$^{27-29}$ although a small proportion of men may suffer stress incontinence for a few weeks after surgery (table 2).

Walsh and Donker's observation that the cavernosal nerves run alongside the prostate, rather than within the capsule, means that in many men the nerves can safely be left intact improving the chance of postoperative potency. The decision on whether to preserve one or both nerve bundles depends on the site and extent of disease at biopsy, as well as preoperative erectile function. Prostate cancer has a tendency to invade perineural spaces and the short inferior neurovascular pedicle at the apex renders extraprostatic extension more common at this site. ${ }^{30}$ In men with extensive apical cancers (the most common site) or high grade disease, it may be appropriate to sacrifice one or both nerve bundles, and potentially potency, in order to achieve cancer cure. In the majority of men though both nerve bundles can be left intact without jeopardising the important goal of total cancer clearance. In the best hands potency can be regained in up to $80 \%$ of men, though this will depend on the age of the patient, the stage of disease, and the number of nerve bundles left intact at the end of the operation. ${ }^{21}$ Men troubled by erectile dysfunction after surgery usually benefit from oral therapies, such as sildenafil; alternatively intraurethral or intracavernosal alprostadil may be used.

\section{External beam radiotherapy}

Standard EBRT offers men with clinically localised disease an alternative to surgery, with similar efficacy but with differing complications. Megavoltage EBRT has been available for over 40 years, but new techniques are developing rapidly. Computed tomography planning allows a clearer assessment of the prostate and surrounding normal tissues. In general two outpatient planning sessions are required before starting treatment, which is performed daily on week days, over a 4-6.5 week period. The radiation dose is limited by the tolerance of normal tissue in the irradiated area and UK doses range from 55-64 Gy.

Cancer control rates as defined as a PSA of $<2 \mathrm{ng} / \mathrm{ml}$ at two years after treatment are between 35\% and $80 \%$ with standard EBRT. ${ }^{31}$ These rates can be improved by increasing the dose of radiotherapy-dose escalation, such that a $10 \%$ increase in dose may improve local control by up to $20 \%{ }^{32}$ Conformal radiotherapy, although not universally available in the UK, provides both dose escalation and better tumour

Table 2 Complication rates after curative treatment for localised prostate cancer (European Association of Urology guidelines; www.uroweb.org)

\begin{tabular}{llll}
\hline Complication & $\begin{array}{l}\text { Radical } \\
\text { prostatectomy } \\
(\%)\end{array}$ & $\begin{array}{l}\text { External beam } \\
\text { radiotherapy } \\
(\%)\end{array}$ & $\begin{array}{l}\text { Brachytherapy } \\
(\%)\end{array}$ \\
\hline $\begin{array}{l}\text { Death } \\
\text { Incontinence }\end{array}$ & $0-2$ & NA & NA \\
$\begin{array}{l}\text { Erectile } \\
\text { dysfunction }\end{array}$ & $20-100$ & $<1$ & $0-19$ \\
$\begin{array}{l}\text { Rectal injury/ } \\
\text { bleeding }\end{array}$ & $<5$ & $10-30$ & $14-38$ \\
$\begin{array}{l}\text { Urinary retention } \\
\text { NA }\end{array}$ & 20 & $1-21$ \\
\hline
\end{tabular}

NA, not applicable. control. This technique allows the irradiated volume to be shaped to match the irregular prostate volume, reducing the normal tissue treated, and thereby the dose limiting side effects from $15 \%$ to $5 \%$ in one study. ${ }^{33}$ Dose escalation appears to benefit particularly men with higher grade disease (Gleason grade $8-10) .^{34}$

A further modification of EBRT is intensity modulated radiotherapy, where differing doses of radiation are given across the irradiated volume, sparing normal structures and delivering higher doses to the tumour. Cancer control using intensity modulated radiotherapy is expected to be superior to conventional EBRT; however, data on cancer outcomes are not yet mature.

\section{Side effects of radiotherapy}

Acute side effects as a result of "normal tissue" exposure usually start towards the end of the fourth week of treatment and peak 10 days after completing EBRT. These include diarrhoea, managed with a low fibre diet and loperamide, tenesmus, and proctitis. Proctosedyl suppositories may be of benefit for the latter symptom. A high fluid intake is recommended to reduce urinary side effects-namely, dysuria and frequency. Lethargy is also experienced especially towards the end of treatment, though this and the other acute side effects usually settle within six weeks of completing EBRT.

Side effects occurring more than three months after the end of EBRT are termed "late side effects" and may include impotence in $10 \%-30 \%$ of men $^{34}$; this may be confounded by the use of adjuvant hormonal therapy, albeit usually temporarily. Incontinence is very unusual and disturbance in stool frequency and consistency occurs in fewer than $20 \%$ of men. A small minority of men develops chronic proctitis giving rise to bleeding and fibrosis, with a $1 \%-2 \%$ risk of surgical intervention. Bowel complications persisting for more than six months require further investigation to exclude an underlying bowel neoplasm (table 2).

\section{Brachytherapy}

This involves the insertion of a radioactive source directly into the prostate, allowing a high dose of radiation to be delivered over a short distance around the source, sparing normal tissue. Two types are used in the treatment of localised prostate cancer: iodine- 125 seeds as a permanent low dose implant and iridium-192 as a temporary, high dose implant used in conjunction with EBRT. The selection criteria are different for both types of treatment and brachytherapy is only available in a few specialist centres.

\section{lodine-125 seeds}

To be considered for seed brachytherapy patients must have a life expectancy exceeding 10 years, clinically localised cancer of Gleason grade 6 or less, a low prostate volume $(<50 \mathrm{ml})$, and no previous prostate surgery. A transrectal ultrasound is performed to assess prostate volume and to plan treatment. Subsequently 20-30 needles are implanted percutaneously using ultrasound guidance. The needles contain up to 120 seeds in total, depending on prostate size and seed activity. The patient receives a spinal or general anaesthetic and is usually in hospital overnight. The largest study with data for 12 years showed $87 \%$ of these "good prognosis" men were PSA-free at 10 years. ${ }^{35}$

Complications occur as a result of radiation damage to the urethra and include both irritative and obstructive urinary symptoms, which may last for up to 60 days - the half life of iodine- 125 . Incontinence rates are reported as $<1 \%$, rising to $50 \%$ in men who have had a transurethral resection of the prostate for benign hyperplasia, hence these patients are now excluded from brachytherapy. Erectile dysfunction occurs in $10 \%-15 \%$ of men (table 2$)^{35 a}$ 


\section{High dose iridium-192 rods}

These are used in men with more unfavourable diseasePSA $>10 \mathrm{ng} / \mathrm{ml}$ or Gleason score $8-10$. They provide a radiation boost and are used in conjunction with a 4.5 week course of EBRT. Hollow rods are positioned in the prostate using ultrasound guidance with the patient under spinal or general anaesthesia. The patient receives three separate doses with a minimum of six hours between each dose. The rods remain in situ throughout the treatment so the patient is kept in the lithotomy position for at least 18 hours. Unsurprisingly backache is a common complaint with this treatment.

The side effects, including incontinence and erectile dysfunction, are similar to EBRT with the added complication associated with the anaesthetic. There is also a risk of urethral stricture in $6 \%$ of men. ${ }^{36}$ PSA-free rates of $79 \%-89 \%$ at five years have been reported in these men with less favourable disease. ${ }^{34}$

\section{Androgen ablation in localised prostate cancer}

In another hormone sensitive cancer, breast cancer, adjuvant therapy has had a highly significant effect on both tumour recurrence and cancer related mortality. ${ }^{37}$ This approach provides a rationale for the use of adjuvant androgen ablation therapy in men with prostate cancer.

\section{Neoadjuvant androgen ablation}

Standard radiotherapy treatment now includes a period of three months of luteinising hormone releasing hormone agonist before EBRT. This allows for the tumour to shrink (cytoreduction), enabling smaller volumes to be treated and so reducing the amount of normal tissue that is irradiated. In addition, a significant difference in local failure rates (32\% v $43 \%$ at eight years in the treated and untreated, respectively) and the progression-free survival has been demonstrated in poor prognosis patients receiving EBRT. ${ }^{38}$

Neoadjuvant androgen deprivation has been shown to reduce the incidence of positive surgical margins and extracapsular disease after surgery in a number of studies. ${ }^{39-41}$ This may be because the whole prostate shrinks allowing wider resection margins, down staging of the tumour itself or because of difficulties with accurate pathological assessment after hormonal treatment. ${ }^{42}$ Either way, there is no evidence from long term prospective randomised trials that neoadjuvant androgen deprivation has any effect on biochemical relapse ${ }^{43} 44$ or survival. ${ }^{45}$ Given the current data the routine use of neoadjuvant androgen deprivation before radical prostatectomy is unjustified. ${ }^{45}$

\section{Adjuvant androgen ablation and EBRT}

Several large studies have confirmed the benefit of at least two years of adjuvant luteinising hormone releasing hormone agonist therapy subsequent to radical radiotherapy for patients with high grade-Gleason score 8-10 tumours. ${ }^{46}$ Significant advantages in disease specific survival and overall survival were seen with a median follow up of over five years. ${ }^{46}$ Both monthly and three monthly depot injections may be used.

The use of adjuvant hormonal therapy in conjunction with standards treatments is currently being assessed in the Early Prostate Cancer Program. This began in 1995 and there are now over 8000 men participating from 23 countries. Men were randomised to receive either bicalutamide (Casodex) $150 \mathrm{mg}$ daily or placebo, in addition to their standard therapy (radical prostatectomy, radiotherapy, or active surveillance). Initial results at three years have shown a reduction of $28 \%$ in the time to progression in men who received bicalutamide compared with the placebo and risk was reduced across all patient groups. ${ }^{47}$ Benefit was seen even in patients with favourable histology and low stage tumours, with a $26 \%$ reduction in disease progression in low grade tumours and
$43 \%$ in high grade disease. Patients in the treatment arm suffered mild or moderate side effects including $66.3 \%$ with gynaecomastia and $72.7 \%$ with breast pain..$^{47}$

Although these early results are promising, the implications of long term hormonal therapy on bone density and endocrine metabolism need to be explored. Furthermore, we need to know the disease specific survival figures before this approach is considered standard.

\section{Adjuvant and salvage treatment after radical prostatectomy}

Prostatic bed radiation after surgery, although becoming more widespread, remains controversial. Potential indications for adjuvant radiotherapy include detectable postoperative $\mathrm{PSA}^{48}$ high Gleason score or extracapsular disease, ${ }^{49}$ seminal vesicle invasion, ${ }^{48}$ lymph node involvement, ${ }^{48-50}$ and positive surgical margins, ${ }^{50} 51$ although studies to date have had small patient numbers. Certainly, reductions in local recurrence rates in patients with positive margins from $23 \%$ to $3 \%$ have been reported with similar results seen in patients with $\mathrm{T} 3$ disease, ${ }^{52}$ but combining EBRT with radical prostatectomy may lead to increased morbidity, particularly in terms of erectile dysfunction and incontinence rates. Furthermore, these improvements in local control have not been translated into a survival benefit.

By definition, giving adjuvant treatment to all high risk cases will result in some patients receiving radiotherapy, with its potential inherent complications, unnecessarily. Some investigators have therefore opted to delay treatment until there is evidence of disease recurrence, either by a detectable or rising PSA or a biopsy proven local recurrence. This raises the question at what PSA threshold should salvage radiotherapy be given if equivalent results to adjuvant therapy are to be achieved?

The American Society of Therapeutic Radiology and Oncology Consensus Panel examined the use of salvage EBRT in patients with PSA relapse after radical prostatectomy. They recommended a dose of at least 64Gy given when the PSA level is less than $1.5 \mathrm{ng} / \mathrm{ml} . .^{53}$ Nudell et al reported a cohort of 105 men treated with either adjuvant or salvage EBRT. $^{54}$ They defined disease-free as the achievement and maintenance of a PSA of $<0.2 \mathrm{ng} / \mathrm{ml}$; giving a five year overall disease-free survival of $43 \%$. Outcomes were equivalent for the adjuvant and salvage EBRT groups where therapeutic irradiation was administered when the serum PSA was $<1.0 \mathrm{ng} / \mathrm{ml}$.

Patients who receive radiotherapy after surgery fare better if the PSA falls to an undetectable level than those with a persistently detectable PSA $(66 \%$ at 40 months compared with $20 \%$ at 12 months, respectively).$^{48}$ What is more, men in whom the PSA rises more than one year after surgery as well as patients who have a low to moderate grade tumour have a better response to salvage EBRT. This is probably as PSA recurrence at this stage is more likely to reflect local recurrence than distant metastases. ${ }^{48}$

Peschel et al reporting on a series of 52 men who had either adjuvant or salvage EBRT found the preoperative PSA level and seminal vesicle involvement were significant risk factors for biochemical recurrence after postoperative radiotherapy. However, the risk of recurrence was most significant for a PSA before radiotherapy of $<0.3 \mathrm{ng} / \mathrm{ml}$, suggesting a PSA threshold of $0.3 \mathrm{ng} / \mathrm{ml} .^{55}$

Not all patients with adverse prognostic indicators or a rising PSA after radical prostatectomy should be considered for radiotherapy. Cadeddu et al found at two years after salvage radiation treatment no patients with Gleason score 8 or more, seminal vesicle invasion, or lymph node metastases were PSA-free. ${ }^{56}$ Patients with lymph node metastases do benefit from adjuvant androgen ablation however. Messing 
et al reported improved overall survival and reduced risk of recurrence in node positive patients treated with goserelin/ orchidectomy rather than observation after radical prostatectomy. $^{57}$

\section{Salvage treatment after radiotherapy failure}

The American Society for Therapeutic Radiology and Oncology define biochemical failure after radical radiotherapy as three consecutive increases in PSA levels at three monthly intervals in the first two years after treatment and six monthly intervals subsequently. ${ }^{58}$ For a PSA failure within one year of radiotherapy and a PSA doubling time of $<8$ months, a $50 \%$ actuarial rate of metastases at three years is seen. Salvage surgery after a biopsy proven recurrence after radiation has a high complication rate, with some series reporting long term incontinence of up to $50 \%$ and early complication rates of $20 \% .^{59}$ It may be considered for selected patients, with no evidence of metastatic disease and a normal World Health Organisation performance status who have been fully consented and reviewed by the multidisciplinary team.

For patients with rising PSA after radical radiotherapy androgen ablation usually with an luteinising hormone releasing hormone agonist remains the treatment choice after restaging. Clinical studies evaluating photodynamic therapy for local recurrence are currently in development, after initial studies using a different photosensitiser were disappointing.

\section{Active surveillance}

Active surveillance or watch and wait involves observing a patient's disease both clinically and with regular PSA measurements and initiating treatment should progression occur. Active treatment is required in $52 \%$ of men under surveillance within five years of diagnosis, ${ }^{60}$ so it would beneficial to try and predict which men will go on to progress. This may help in therapeutic decision making and allow the frequency of follow up to be tailored to the individual should a watch and wait policy be adopted.

Several studies have shown that the rate of progression in men under surveillance is linked to their Gleason grade and their PSA at diagnosis. ${ }^{61-65}$ A pooled analysis of 828 patients with clinically localised disease demonstrated that higher grade disease enhanced the likelihood of both metastases and death from prostate cancer. ${ }^{61}$ At 10 years the disease specific survival was $87 \%$ for men with low and moderate grade disease(Gleason 2-7), but 34\% for men with high grade disease (Gleason 8-10) (table 3). These results were supported by a large population based study from the US involving nearly 60000 men with clinically localised prostate cancer. In this series, the 10 year cancer specific survival rates were $92 \%$ for men with low grade (Gleason 2-4), 76\% with moderate grade (Gleason 5-7), and 43\% for patients with high grade (Gleason $8-10$ ) disease. ${ }^{64}$

\begin{tabular}{|c|c|c|}
\hline & \multicolumn{2}{|c|}{ Percent of patients $(95 \% \mathrm{Cl})$} \\
\hline & 5 years & 10 years \\
\hline \multicolumn{3}{|c|}{ Disease specific survival } \\
\hline Grade 1 & $98(96$ to 99$)$ & 87 (81 to 91$)$ \\
\hline Grade 2 & 97 (93 to 98 ) & 87 (80 to 92$)$ \\
\hline Grade 3 & $67(51$ to 79$)$ & $34(19$ to 50$)$ \\
\hline \multicolumn{3}{|c|}{ Metastasis-free survival } \\
\hline Grade 1 & $93(90$ to 95$)$ & $81(75$ to 86$)$ \\
\hline Grade 2 & 84 (79 to 89 ) & 58 (49 to 66 ) \\
\hline Grade 3 & 51 (36 to 64) & 26 (13 to 41$)$ \\
\hline
\end{tabular}

The role of serum PSA as a predictor of disease progression in men under active surveillance was assessed in a Swedish study which selected 658 well men born in 1913 who were 67 years old at randomisation. ${ }^{65}$ A blood sample was extracted and stored frozen and the group followed up for 15 years. The patients' management was according to local protocols and no patient had PSA screening or curative treatment for prostate cancer. In total $52(7.9 \%)$ men developed clinical prostate cancer. The authors reported that the risk of developing prostate cancer and of dying of the disease was related to the serum PSA at age 67. If at the age of 67 the PSA was $<3 \mathrm{ng} / \mathrm{ml}, 5 \%$ developed clinical cancer; if the PSA was $3-10 \mathrm{ng} / \mathrm{ml}, 30 \%$ developed the disease; and if the PSA was $>10 \mathrm{ng} / \mathrm{ml}, 50 \%$ men developed clinical prostate cancer.

In patients with a low PSA, low grade and clinically localised disease active surveillance maybe a safe option, likewise in men with a limited life expectancy observation may be preferable to the side effects of treatment. However, it should not be assumed that patients diagnosed with localised prostate cancer who are observed have a better quality of life than those undergoing treatment. In a subsidiary part of the Holmberg study comparing radical prostatectomy with active surveillance a quality of life questionnaire was also completed by 326 participants assessing erectile, urinary, and bowel dysfunction as well as anxiety, depression, and general wellbeing. ${ }^{66}$ In the majority of men nerve sparing surgery was not performed so unsurprisingly erectile dysfunction occurred in $80 \%$ undergoing surgery compared with $45 \%$ in the expectant group, though sexual function was considered less important in the radical prostatectomy cohort. Patients in the surgical group reported a higher incidence of urinary leakage; however, a weak urinary stream was reported in $28 \%$ assigned radical prostatectomy and $44 \%$ of men assigned watchful waiting.

The study also examined psychological variables including worry, anxiety, depression, wellbeing, and subjective quality of life. Although a lower prevalence of deleterious psychological symptoms was found in the radical prostatectomy group, all the confidence intervals for the relative risks included 1. The authors concluded their data supported no difference between the two groups in this area. ${ }^{66}$

\section{CONCLUSIONS}

The ageing population and the increasing awareness of PSA and prostate cancer means that the number of men requiring treatment for prostate cancer will continue to rise. Patients with localised disease now have a choice of treatments with comparable cancer outcomes but with differing side effects. For patients opting to have active surveillance more is known about risk factors of progression, and clinicians should be aware that patients under surveillance suffer similar rates of psychological symptoms.

\section{Authors' affiliations}

S R J Bott, A J Birtle, C J Taylor, Institute of Urology, London

R S Kirby, St George's Hospital, London

\section{REFERENCES}

1 Scardino PT, Weaver R, Hudson MA. Early detection of prostate cancer. Hum Pathol 1992;23:211-22.

2 Stamey TA, Yang N, Hay AR, et al. Prostate-specific antigen as a serum marker for adenocarcinoma of the prostate. N Engl J Med 1987;317:909-16.

3 Shibata A, Whittemore AS. Re: prostate cancer incidence and mortality in the United States and the United Kingdom. J Nat Cancer Inst 2001;93:1 109-10.

4 Welch HG, Schwartz LM, Woloshin S. Are increasing 5-year survival rates evidence of success against cancer? JAMA 2000;283:2975-8.

5 Walsh PC. Surgery and the reduction of mortality from prostate cancer. N Engl J Med 2002;347:839-40.

6 Han M, Partin AW, Piantadosi S, et al. Era specific biochemical recurrencefree survival following radical prostatectomy for clinically localized prostate cancer. J Urol 2001;166:416-19. 
7 Brawley OW. Prostate carcinoma incidence and patient mortality: the effects of screening and early detection. Cancer 1997;80:1857-63.

8 British Association of Urological Surgeons. Analysis of minimum data set for urological cancers. (Chart 61, 47.) London: British Association of Urological Surgeons, 2002.

9 Graefen M, Karakiewicz PI, Cagiannos I, et al. International validation of a preoperative nomogram for prostate cancer recurrence after radical prostatectomy. J Clin Oncol 2002;20:3206-12.

10 Poon M, Ruckle H, Bamshad BR, et al. Radical retropubic prostatectomy: bladder neck preservation versus reconstruction. J Urol 2000;163:194-8.

11 Guillonneau B, Vallancien G. Laparoscopic radical prostatectomy: the Montsouris technique. J Urol 2000;163:1643-9.

12 Partin AW, Kattan MW, Subong EN, et al. Combination of prostate-specific antigen, clinical stage, and Gleason score to predict pathological stage of localized prostate cancer. A multi-institutional update. JAMA 1997;277:1445-51.

13 Epstein JI, Pizov G, Walsh PC. Correlation of pathologic findings with progression after radical retropubic prostatectomy. Cancer 1993;71:3582-93.

14 Sakr WA, Wheeler TM, Blute M, et al. Staging and reporting of prostate cancer-sampling of the radical prostatectomy specimen. Cancer 1996;78:366-8.

15 Abbou CC, Salomon L, Hoznek A, et al. Laparoscopic radical prostatectomy: preliminary results. Urology 2000:55:630-4.

16 Weldon VE, Tavel FR, Neuwirth H. Continence, potency and morbidity after radical perineal prostatectomy. $J$ Urol 1997; 158:1470-5.

17 Frazier HA, Robertson JE, Paulson DF. Radical prostatectomy: the pros and cons of the perineal versus retropubic approach. J Urol 1992;147/3 pt 2):888-90.

18 Eden CG, Cahill D, Vass JA, et al. Laparoscopic radical prostatectomy: the initial UK series. BJU Int 2002;90:876-82.

19 Bollens R, Vanden Bossche M, Roumeguere T, et al. Extraperitoneal laparoscopic radical prostatectomy. Results after 50 cases. Eur Urol 2001:40:65-9.

20 Babaian RJ, Troncoso P, Bhadkamkar VA, et al. Analysis of clinicopathologic factors predicting outcome after radical prostatectomy. Cancer 2001;91:1414-22.

21 Walsh PC, Partin AW, Epstein Jl. Cancer control and quality of life following anatomical radical retropubic prostatectomy: results at 10 years. J Urol 1994;152(5 pt 2):1831-6.

22 Catalona WJ, Ramos CG, Carvalhal GF. Contemporary results of anatomic radical prostatectomy. CA Cancer I Clin 1999:49:282-96.

23 Bott SRJ, Thomas K, Foley C, et al. Cancer control, continence and potency affer radical prostatectomy - a UK series. British Association of Urological Surgeons annual meeting, Glasgow 2002 (abstract 117).

24 Holmberg L, Bill-Axelson A, Helgesen F, et al. A randomized trial comparing radical prostatectomy with watchful waiting in early prostate cancer. N Engl J Med 2002;347:781-9.

25 Pound CR, Partin AW, Eisenberger MA, et al. Natural history of progression after PSA elevation following radical prostatectomy. JAMA 1999:281:1591-7.

26 Walsh PC, Donker PJ. Impotence following radical prostatectomy: insight into etiology and prevention. J Urol 1982;128:492-7.

27 Catalona WJ, Carvalhal GF, Mager DE, et al. Potency, continence and complication rates in 1,870 consecutive radical retropubic prostatectomies. J Urol 1999:162:433-8.

28 Walsh PC. Patient-reported urinary continence and sexual function after anatomic radical prostatectomy. J Urol 2000;164:242.

29 Salomon L, Anastasiadis AG, Katz R, et al. Urinary continence and erectile function: a prospective evaluation of functional results affer radical laparoscopic prostatectomy. Eur Urol 2002;42:338-43.

30 Stamey TA, Villers AA, McNeal JE, et al. Positive surgical margins at radical prostatectomy: importance of the apical dissection. J Urol 1990;143:1166-72.

31 Horwich A, Wynne C, Nahum A, et al. Conformal radiotherapy at the Royal Marsden Hospital (UK). Int J Radiat Biol 1994:65:117-22.

32 Hanks GE, Hanlon AL, Epstein B, et al. Dose response in prostate cancer with 8-12 years' follow-up. Int J Radiat Oncol Biol Phys 2002;54:427-35.

33 Nutting CM, Dearnaley DP. Prostate cancer-the Royal Marsden conformal experience. Front Radiat Ther Oncol 2002;37:196-9.

34 Martinez AA, Gustafson G, Gonzalez J, et al. Dose escalation using conformal high-dose-rate brachytherapy improves outcome in unfavorable prostate cancer. Int J Radiat Oncol Biol Phys 2002;53:316-27.

35 Blasko JC, Mate T, Sylvester JE, et al. Brachytherapy for carcinoma of the prostate: techniques, patient selection, and clinical outcomes. Semin Radiat Oncol 2002;12:81-94.

35a Stone NN, Stock RG. Complications following permanent prostate brachytherapy. Eur Urol 2002;41:427-33.

36 Dearnaley DP, Khoo VS, Norman AR, et al. Comparison of radiation sideeffects of conformal and conventional radiotherapy in prostate cancer: a randomised trial. Lancet 1999;353:267-72.

37 Early Breast Cancer Trialists' Collaborative Group. Systemic treatment of early breast cancer by hormonal, cytotoxic, or immune therapy. 133 randomised trials involving 31000 recurrences and 24000 deaths among 75,000 women. Lancet 1992;339:1-15.

38 Pilepich MV, Winter K, John MJ, et al. Phase III radiation therapy oncology group (RTOG) trial 86-10 of androgen deprivation adjuvant to definitive radiotherapy in locally advanced carcinoma of the prostate. Int $J$ Radiat Oncol Biol Phys 2001:50:1243-52.

39 Montironi R, Diamanti L, Santinelli A, et al. Effect of total androgen ablation on pathologic stage and resection limit status of prostate cancer. Initial results of the Italian PROSIT study. Pathol Res Pract 1999;195:201-8.
40 Soloway MS, Sharifi R, Wajsman Z, et al. Randomized prospective study comparing radical prostatectomy alone versus radical prostatectomy preceded by androgen blockade in clinical stage $\mathrm{B} 2(\mathrm{~T} 2 \mathrm{bNxMO}$ ) prostate cancer. The Lupron Depot Neoadjuvant Prostate Cancer Study Group. J Urol 1995:154(2 pt 1):424-8.

41 Van Poppel H, De Ridder D, Elgamal AA, et al. Neoadjuvant hormonal therapy before radical prostatectomy decreases the number of positive surgical margins in stage T2 prostate cancer: interim results of a prospective randomized trial. The Belgian Uro-Oncological Study Group. J Urol 1995;154(2 pt 1):429-34.

42 Wieder JA, Soloway MS. Incidence, etiology, location, prevention and treatment of positive surgical margins after radical prostatectomy for prostate cancer. J Urol 1998:160:299-315.

43 Soloway MS, et al. Radical prostatectomy alone versus radical prostatectomy preceded by androgen blockade in cT2b prostate cancer-24 month results. $J$ Urol 1997; 157:160 (abstract 619).

44 Goldenberg S, et al. A randomised trial of neoadjuvant androgen withdrawl therapy prior to radical prostatectomy: 24 month post-treatment PSA results. J Urol 1997; 157(part2):92 (abstract 357).

45 Lee HH, Warde P, Jewett MA. Neoadjuvant hormonal therapy in carcinoma of the prostate. BJU Int 1999:83:438-48.

46 Lawton CA, Winter K, Murray K, et al. Updated results of the phase III Radiation Therapy Oncology Group (RTOG) trial 85-31 evaluating the potential benefit of androgen suppression following standard radiation therapy for unfavorable prognosis carcinoma of the prostate. Int $J$ Radiat Oncol Biol Phys 2001:49:937-46.

47 See WA, Wirth MP, McLeod DG, et al. Bicalutamide as immediate therapy either alone or as adjuvant to standard care of patients with localized or locally advanced prostate cancer: first analysis of the early prostate cance program. J Urol 2002;168:429-35.

48 Coetzee U, Hars V, Paulson DF. Postoperative prostate-specific antigen as a prognostic indicator in patients with margin-positive prostate cancer, undergoing adjuvant radiotherapy after radical prostatectomy. Urology 1996;47:232-5.

49 Zincke $\mathrm{H}$, Oesterling JE, Blute ML, et al. Long-term (15 years) results after radical prostatectomy for clinically localized (stage T2c or lower) prostate cancer. J Urol 1994;152(5 pt 2):1850-7.

50 Pound CR, Partin AW, Epstein Jl, et al. Prostate-specific antigen after anatomic radical retropubic prostatectomy. Patterns of recurrence and cancer control. Urol Clin North Am 1997:24:395-406.

51 Blute ML, Bostwick DG, Seay TM, et al. Pathologic classification of prostate carcinoma: the impact of margin status. Cancer 1998;82:902-8.

52 Valicenti RK, Gomella LG, Ismail M, et al. The efficacy of early adjuvan radiation therapy for pT3NO prostate cancer: a matched-pair analysis. Int J Radiat Oncol Biol Phys 1999;45:53-8.

53 Cox JD, Gallagher MJ, Hammond EH, et al. Consensus statements on radiation therapy of prostate cancer: guidelines for prostate re-biopsy after radiation and for radiation therapy with rising prostate-specific antigen levels after radical prostatectomy. American Society for Therapeutic Radiology and Oncology Consensus Panel. J Clin Oncol 1999;17:1155.

54 Nudell DM, Grossfeld GD, Weinberg VK, et al. Radiotherapy after radical prostatectomy: treatment outcomes and failure patterns. Urology 1999:54:1049-57.

55 Peschel RE, Robnett TJ, Hesse D, et al. PSA based review of adjuvant and salvage radiation therapy vs observation in postoperative prostate cancer patients. Int J Cancer 2000;90:29-36.

56 Cadeddu JA, Partin AW, De Weese TL. Long-term results of radiation therapy for prostate cancer recurrence following radical prostatectomy. J Urol 1998;159:173-7.

57 Messing EM, Manola J, Sarosdy M, et al. Immediate hormonal therapy compared with observation after radical prostatectomy and pelvic lymphadenectomy in men with node-positive prostate cancer. N Engl J Med 1999;341:1781-8

58 American Society for Therapeutic Radiology and Oncology Consensus Panel. Consensus statement: guidelines for PSA following radiation therapy. Int J Radiat Oncol Biol Phys 1997:37:1035-41.

59 Stein A, Smith RB, deKernion JB. Salvage radical prostatectomy after failure of curative radiotherapy for adenocarcinoma of prostate. Urology 1992:40:197-200

60 Koppie TM, Grossfeld GD, Miller D, et al. Patterns of treatment of patients with prostate cancer initially managed with surveillance: results from The CaPSURE database. Cancer of the Prostate Strategic Urological Research Endeavor. $J$ Urol 2000;164:81-8.

61 Chodak GW, Thisted RA, Gerber GS, et al. Results of conservative management of clinically localized prostate cancer. N Engl J Med 1994;330:242-8.

62 Albertsen PC, Fryback DG, Storer BE, et al. Long-term survival among men with conservatively treated localized prostate cancer. JAMA 1995:274:626-31.

63 Albertsen PC, Hanley JA, Gleason DF, et al. Competing risk analysis of men aged 55 to 74 years at diagnosis managed conservatively for clinically localized prostate cancer. JAMA 1998:280:975-80.

64 Lu-Yao GL, Yao SL. Population-based study of long-term survival in patients with clinically localised prostate cancer. Lancet 1997;349:906-10.

65 Hugosson J, Aus G, Becker C, et al. Would prostate cancer detected by screening with prostate-specific antigen develop into clinical cancer if left undiagnosed? A comparison of two population-based studies in Sweden. ВЛU Int 2000;85:1078-84.

66 Steineck G, Helgesen F, Adolfsson J, et al. Quality of life after radical prostatectomy or watchful waiting. N Engl J Med 2002;347:790-6. 